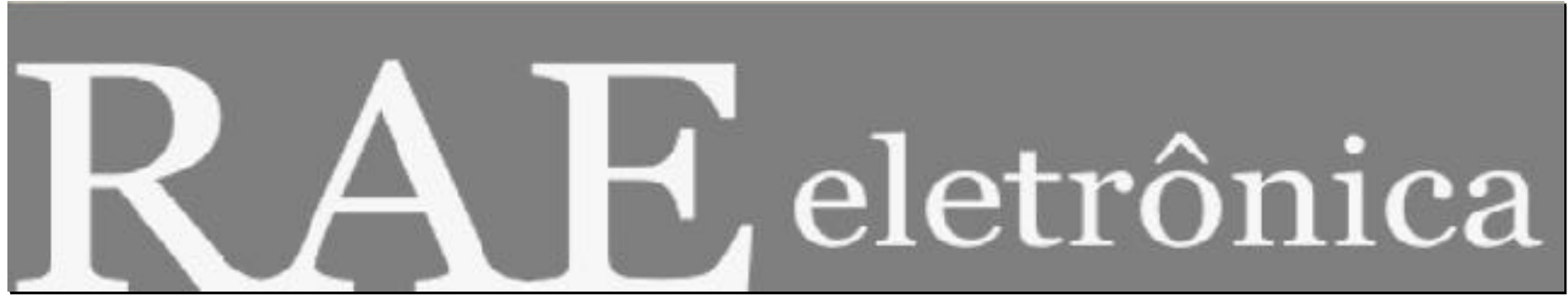

\title{
GESTÃO DE INOVAÇÃO: A LEI DE INOVAÇÃO TECNOLÓGICA COMO FERRAMENTA DE APOIO ÀS POLÍTICAS INDUSTRIAL E TECNOLÓGICA DO BRASIL
}

Por:

José Matias-Pereira, UNB

Isak Kruglianskas, USP

RAE-eletrônica, v. 4, n. 2, Art. 18, jul./dez. 2005

http://www.rae.com.br/eletronica/index.cfm?FuseAction=Artigo \&ID=1912\&Secao=ARTIGOS\&Volu $\mathrm{me}=4 \&$ Numero $=2 \& \mathrm{Ano}=2005$

CCopyright, 2005, RAE-eletrônica. Todos os direitos, inclusive de tradução, são reservados. É permitido citar parte de artigos sem autorização prévia desde que seja identificada a fonte. A reprodução total de artigos é proibida. Os artigos só devem ser usados para uso pessoal e nãocomercial. Em caso de dúvidas, consulte a redação: raeredacao@fgvsp.br.

A RAE-eletrônica é a revista on-line da FGV-EAESP, totalmente aberta e criada com o objetivo de agilizar a veiculação de trabalhos inéditos. Lançada em janeiro de 2002, com perfil acadêmico, é dedicada a professores, pesquisadores e estudantes. Para mais informações consulte o site www.rae.com.br/eletronica.

RAE-eletrônica

ISSN 1676-5648

(C2005 Fundação Getulio Vargas - Escola de Administração

de Empresas de São Paulo.

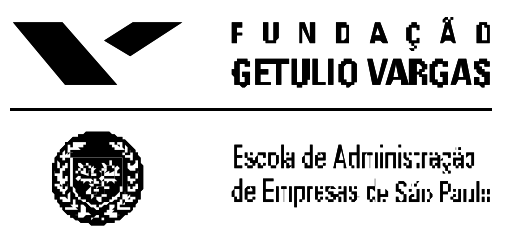




\title{
GESTÃO DE INOVAÇÃO: A LEI DE INOVAÇÃO TECNOLÓGICA COMO FERRAMENTA DE APOIO ÀS POLÍTICAS INDUSTRIAL E TECNOLÓGICA DO BRASIL \\ José Matias -Pereira - Isak Kruglianskas
}

\section{RESUMO}

O objetivo principal deste artigo é debater, a partir das experiências de alguns países bem-sucedidos na implementação de políticas industrial e tecnológica, se a construção de um moderno arcabouço institucional na área de desenvolvimento científico e tecnológico, no qual deve estar incluída a questão da inovação, é essencial para o crescimento econômico do País. Nesse esforço, buscamos aprofundar a discussão sobre as políticas de gestão da inovação no Brasil, em especial sobre a Lei de Inovação Tecnológica - LIT (Lei Federal n. ${ }^{\circ} 10.973$ de 02.12.2004) - que estabelece medidas de incentivo à inovação e à pesquisa científica e tecnológica no ambiente produtivo, com vistas à capacitação e ao alcance da autonomia tecnológica e ao desenvolvimento industrial do País, por meio da análise das principais medidas explicitadas em seu texto. Evidencia-se que a aprovação da Lei de Inovação Tecnológica, apesar de suas deficiências, representa um instrumento relevante de apoio às políticas industrial e tecnológica do Brasil.

\begin{abstract}
The main objective of this article is to debate, from the experiences of some successful countries in industrial and technological implementation of politics, if the construction of an institutional modern system in the area of scientific and technological development, in which must be enclosed the question of innovation, is essential for the economic growth of the country. In this effort, we search to deepen the quarrel on the politics of management of innovation in Brazil, in special on the Law of Technological Innovation - LIT (Federal Law $n^{\circ}$ 10,973, 02.12.2004) - that establishes measurements of incentive to innovation and the scientific and technological research in the productive environment, with sights to the qualification and the reach of the technological autonomy and to the industrial development of the country through the analysis of the main measures defined in its text. It is an evidence that the approval of the innovation law, although its deficiencies, represents an excellent instrument of support to the industrial and technological politics of Brazil.
\end{abstract}

\section{PALAVRAS-CHAVE}

Lei de Inovação Tecnológica, políticas industrial e tecnológica, crescimento econômico, desenvolvimento, Brasil.

\section{KEYWORDS}

Law of technological innovation, industrial and technological politics, economic growth, development, Brazil. 


\section{INTRODUÇÃO}

Em uma economia sólida, a inovação tecnológica deve ser resultado de um ambiente que produz ciência de ponta e influencia direta e indiretamente o setor produtivo, especialmente por meio dos setores de pesquisa e desenvolvimento gerados no bojo das empresas. Verificamos, entretanto, que o modelo de desenvolvimento adotado no Brasil, nas últimas décadas, não criou condições e estímulos para que as empresas passassem a ter tais setores em suas estruturas. Essas distorções estão refletidas na produção científica do País, particularmente aquela proveniente das universidades públicas, que representam uma parcela significativa da produção nacional. Essa constatação nos permite argumentar que o Brasil é um país que produz ciência de fronteira, mas que não consegue interagir, em um nível adequado, com o setor produtivo. O resultado dessa baixa incorporação de tecnologia de ponta diretamente nos produtos torna-os pouco competitivos, tanto no mercado interno como no externo. Criar as condições para que o País consiga avançar de forma consistente no campo tecnológico é uma tarefa árdua, que exige, além da mudança institucional e econômica, também uma mudança cultural. Torna-se perceptível, assim, que a mola propulsora para viabilizar o aumento da produção científica e tecnológica no País tem início com a criação de instrumentos reguladores dessa relação.

Apesar de a Constituição Federal do Brasil (CF, 1988) ter definido, em grandes linhas, o papel do Estado brasileiro nas diversas atividades, fortalecendo o Estado articulador, promotor e incentivador, na prática a ação do Estado em relação a C\&T ainda deixa muito a desejar (Caldas, 2001). Apenas nos últimos anos a ação estratégica começou a ser delineada, com a elaboração dos Planos Plurianuais e a construção de um plano estratégico para a ciência, a tecnologia e a inovação. Tendo como referência os preceitos constitucionais estabelecidos no artigo 218 da Constituição Federal, que estabelece que o Estado promoverá e incentivará o desenvolvimento científico, a pesquisa e a capacitação tecnológicas, o Ministério da Ciência e Tecnologia (MCT) elaborou o "Projeto de Diretrizes Estratégicas para a Ciência, Tecnologia e Inovação em um Horizonte de 10 Anos" (DECTI). O projeto de DECTI/MCT foi estruturado em cinco grandes temas: "No caminho do Futuro" - focado em educação para a ciência e tecnologia e no avanço do conhecimento; "Qualidade de Vida" - focado no impacto do desenvolvimento científico e tecnológico sobre o cidadão e sobre o meio ambiente, com vistas à promoção de desenvolvimento sustentável; "Desenvolvimento econômico" - focado em C\&T sob o ângulo econômico - produção de bens e serviços em uma sociedade marcada por sérias desigualdades regionais e sociais; "Desafios Estratégicos" - focado nos grandes programas de impacto para a próxima década, tais como a sociedade da informação e a biotecnologia, nos projetos mobilizadores nacionais e nas estratégias de exploração econômica das últimas fronteiras brasileiras; e "Desafios Institucionais" - focado nos desafios legais, institucionais e de organização a serem superados para que as metas propostas no projeto possam ser alcançadas.

É este último tema - desafios institucionais - que o presente trabalho irá abordar. Terá como preocupação analisar e aprofundar a discussão sobre a importância da construção de um arcabouço legal que contribua para uma maior integração entre o desenvolvimento científico e tecnológico e a produção de inovação. Nesse esforço, iremos utilizar como referência a Lei de Inovação Tecnológica (Lei Federal n. ${ }^{\circ}$ 10.973/2004), que "dispõe sobre incentivos à inovação e à pesquisa científica e tecnológica no ambiente produtivo e dá outras providências". A referida lei tem como objetivo criar um ambiente propício para aumentar o envolvimento das empresas no desenvolvimento de projetos 


\section{GESTÃO DE INOVAÇÃO: A LEI DE INOVAÇÃO TECNOLÓGICA COMO FERRAMENTA DE APOIO ÀS POLÍTICAS INDUSTRIAL E TECNOLÓGICA DO BRASIL \\ José Matias -Pereira - Isak Kruglianskas}

inovadores que levem a gerar novos produtos e processos. Busca-se, com ela, uma elevação do nível de parcerias entre empresas, universidades e institutos científicos e tecnológicos para que ganhem força e estimulem o processo de inovação.

\section{POLÍTICAS INDUSTRIAL E TECNOLÓGICA E A LEI DE INOVAÇÃO TECNOLÓGICA}

O tema abordado neste artigo é significativamente amplo, complexo e polêmico, visto que existe uma parcela da comunidade científica que discorda da necessidade de que se tenha uma "política de inovação" tecnológica. A base de argumentação desse segmento da comunidade científica é de que deve prevalecer sempre a ampla liberdade do pesquisador de determinar o objeto e o escopo de suas pesquisas, ao passo que, ao poder público, fica o papel de financiamento das atividades de pesquisa. Aceitamos, neste artigo, que é relevante e necessária a existência de uma política nessa área.

No debate sobre a construção de uma política industrial e tecnológica e de uma lei de inovação torna-se relevante fazer uma análise do Sistema de Ciência e Tecnologia do Brasil (SCTB). Assim, iremos adotar neste artigo, de maneira preferencial, uma abordagem funcionalista e sistêmica em que as organizações e relações foram, inicialmente, consideradas como instituições "tipo-ideal" weberianas, a fim de facilitar a identificação e o estudo dos elementos que formam esse complexo sistema. Levaremos em consideração também o conceito de "racionalidade limitada" de Herbert Simon (1959, 1965, 1978). Assim, partimos do pressuposto de que o SCTB, apesar de apoiar-se em uma base estrutural razoável, necessita ser fortalecido de várias maneiras para que possa ser ampliado, consolidado e garantido contra eventuais instabilidades no futuro.

Sustenta Morgan (1980) que a abordagem funcionalista é essencialmente ortodoxa e que ela é "baseada na pressuposição de que a sociedade tem uma existência concreta e real, e um caráter sistêmico orientado para produzir um estado de coisas que sejam ordenadas e reguladas". Ao estabelecer a distinção entre estabilidade e mudança como aspectos específicos da ordem e do conflito, respectivamente, Dahrendorf (1959) alerta que não tem a intenção de afirmar que a teoria da ordem assume que a sociedade seja estática (Burrell e Morgan, 1979). Sua preocupação é mostrar como as teorias funcionais são essencialmente correlacionadas com os processos que servem para manter os padrões de um sistema como um todo. Nesse sentido, as teorias funcionalistas são consideradas como estáticas no sentido em que procuram explicar o status quo. Aguiar (1991), utilizando o método de análise funcional para descrever a ambiência de ciência e da tecnologia no Brasil, busca explicar como os elementos que compõem o sistema nacional procuram se estabilizar, se integrar e atuar harmonicamente. 


\section{GESTÃO DE INOVAÇÃO: A LEI DE INOVAÇÃO TECNOLÓGICA COMO FERRAMENTA DE APOIO ÀS \\ POLÍTICAS INDUSTRIAL E TECNOLÓGICA DO BRASIL \\ José Matias -Pereira - Isak Kruglianskas}

\section{FUNDAMENTOS PARA A CONSTRUÇÃO DE UM MODELO TECNOLÓGICO}

A agressiva disputa pela apropriação da informação, do conhecimento e do desenvolvimento da inovação no mundo contemporâneo, decorrente do processo de globalização, conforme delineado nas conclusões do Livro Branco da Ciência, Tecnologia e Inovação (MCT, 2002), indica a necessidade de o Brasil construir um modelo de desenvolvimento tecnológico autônomo. Isso torna explícito que a Lei de Inovação Tecnológica, cujo teor deve refletir claramente que a geração de conhecimento e a formação de recursos humanos são funções da universidade, e que a inovação tecnológica ocorre no âmbito das empresas, se apresenta como um instrumento relevante para reduzir a dependência tecnológica do País.

Registre-se aqui que inovação tecnológica compreende a introdução de produtos ou processos tecnologicamente novos e melhorias significativas que tenham sido implementadas em produtos e processos existentes. Considera-se uma inovação tecnológica de produto ou processo aquela que tenha sido implementada e introduzida no mercado - inovação de produto - ou utilizada no processo de produção - inovação de processo - (OCDE, Manual Oslo, p. 35).

A partir dessas observações, formula-se a seguinte pergunta: a Lei de Inovação Tecnológica aceita como parte essencial do arcabouço institucional para fortalecer as áreas de pesquisa e da produção de conhecimento no Brasil - poderá fomentar adequadamente a criação de novos ambientes, propícios à geração e absorção de inovações, atuando como instrumento de apoio às políticas industrial e tecnológica do Brasil?

Para responder essa indagação, parte-se do pressuposto de que o Brasil ainda não construiu um arcabouço institucional na área científico-tecnológica suficientemente consistente capaz de definir adequadamente quais são as atividades de pesquisa de real interesse tecnológico para o País. Assim, temos como propósito debater neste artigo, a partir das experiências de alguns países bem-sucedidos na implementação de políticas industrial e tecnológica, se a construção de um moderno arcabouço institucional na área de desenvolvimento científico e tecnológico, no qual deve estar incluída a questão da inovação, é essencial para o crescimento econômico do Brasil. A investigação, que é explicativa quanto aos fins e bibliográfica quanto aos meios, está apoiada em vários estudos e documentos, como, por exemplo, Dahlman e Frischtak (1990), Brisolla (1993), Azevedo (1994), Gibbons, Limonges et al. (1994), Cassiolato (1996), Pavitt (1991, 1998), Coutinho (1999), Coutinho e Ferraz (1994), Eber (2000), Schwartzman (2001), Matias-Pereira e Kruglianskas (2004), Matias-Pereira, Kruglianskas e Marcelino (2005), Livro Branco da Ciência, Tecnologia e Inovação (MCT, 2002), Diretrizes de Política Industrial, Tecnológica e de Comércio Exterior (PITCE/MDICE, 2003), e na Lei de Inovação Tecnológica (Lei Federal n. ${ }^{\circ}$ 10.973/2004).

\section{Análise das experiências de países de sucesso na promoção de C\&T}

A abordagem da experiência em CT\&I de alguns países bem-sucedidos nessas áreas é oportuna para a compreensão do propósito deste estudo. Argumenta-se que tanto o Parlamento como a sociedade organizada brasileira, na discussão para promover o aperfeiçoamento do projeto de lei de inovação 


\section{GESTÃO DE INOVAÇÃO: A LEI DE INOVAÇÃO TECNOLÓGICA COMO FERRAMENTA DE APOIO ÀS POLÍTICAS INDUSTRIAL E TECNOLÓGICA DO BRASIL \\ José Matias -Pereira - Isak Kruglianskas}

brasileira, precisam levar em consideração as estratégias que esses países adotaram em C\&T para fomentar o processo de desenvolvimento econômico e social.

Na maior parte dos países integrantes da Organização de Cooperação e Desenvolvimento Econômico (OCDE, 1996 e 1997b), os governos estão adotando políticas para contrapor os efeitos provocados pelo nível elevado de abertura ao exterior que se seguiu à importante redução de barreiras tarifárias que foram implementadas. As políticas de competitividade adotadas nos países da OCDE (1996), visando ao aumento das exportações, estão orientadas de forma seletiva. Tem havido uma diminuição dos subsídios diretos às empresas e ênfase no apoio ao investimento em setores intensivos em tecnologia e à constituição de infra-estrutura necessária para alcançar objetivos de crescimento de longo prazo. As pequenas e médias empresas e a organização de clusters industriais recebem tratamento diferenciado na alocação dos investimentos. Naqueles países a política industrial é percebida de uma maneira mais ampla e sua função é articular e envolver empresas de diferentes setores e atividades, tendo as tecnologias de informação e as comunicações como molas impulsoras do processo (Lastres e Albagli, 1999; Lora, 2001).

Com base na experiência dos países industrializados, argumenta-se que o caminho para o desenvolvimento econômico e social passa, necessariamente, pela eficiência tecnológica (Matesco, 2001). Essa realidade é reforçada, também, pelo sucesso de alguns países emerge ntes que estão gerando riqueza a partir do conhecimento alcançado em centros de pesquisa (Maldonado, 1998). A descrição feita a seguir tem como objetivo explicitar as experiências da Coréia do Sul, França, Estados Unidos e Japão, cujas políticas industriais e tecnológicas refletem e influenciam os debates sobre o tema no Brasil.

\section{Coréia do Sul}

A Coréia, por meio da Lei n. 1.864 , promulgada em 1967, denominada "Lei da Promoção de C\&T", deflagrou o processo de consolidação do desenvolvimento tecnológico e à criação das infra-estruturas de C\&T naquele país, com base no modelo learning by doing. Posteriormente, em 1989, foi promulgada a Lei n. ${ }^{\circ}$ 4.196, conhecida como "Lei da Promoção da Pesquisa Básica", que expressa a visão política de que a inovação depende essencialmente da capacidade inventiva do país para fazer face ao novo modelo de desenvolvimento industrial learning by research. Com a aceleração do processo de industrialização ocorrido na Coréia, a partir da década de 1970, a principal vertente de desenvolvimento econômico daquele país foi a de trabalhadores altamente qualificados com salários relativamente baixos, com altas taxas de poupança e mecanismos de proteção das indústrias nacionais (Shin et al., 1994). A vantagem comparativa da Coréia com base nesses fatores não é mais efetiva, uma vez que não estão mais disponíveis recursos ociosos e a economia encontra-se plenamente aberta ao mundo. Constata-se que o ambiente econômico está mudando rapidamente na Coréia à medida que avança a globalização e, portanto, estão aumentando as necessidades de mudança nas políticas públicas com vistas a uma transição bem-sucedida para uma economia baseada no conhecimento naquele país (Stepi, 1995). A implicação, nesse caso, é que a Coréia está buscando identificar outras fontes de vantagens comparativas, principalmente em atividades de C\&T.

Registre-se aqui que um dos modelos bem-sucedidos de prospecção tecnológica foi elaborado quando o MCT concluiu, em 1992, um programa nacional de P\&D denominado Projetos Nacionais Altamente Avançados. O propósito desses projetos era potencializar a competitividade das indústrias 


\section{GESTÃO DE INOVAÇÃO: A LEI DE INOVAÇÃO TECNOLÓGICA COMO FERRAMENTA DE APOIO ÀS POLÍTICAS INDUSTRIAL E TECNOLÓGICA DO BRASIL \\ José Matias -Pereira - Isak Kruglianskas}

nacionais mediante o aumento da capacidade local em ciência e tecnologia. Naquela fase, a política de C\&T na Coréia carecia de unidade no planejamento de C\&T. Isso se deve, em grande parte, ao sistema diversificado de formulação da política de C\&T naquele país. Uma avaliação dos Projetos Altamente Avançados (HAN - Highly Advanced Projects), três anos após o seu início, evidenciou que a iniciativa dos projetos HAN foi bem-sucedida. Essa iniciativa tem sido considerada na formulação de grandes políticas no setor de C\&T na Coréia, como foi o caso da elaboração da Lei Especial sobre C\&T em 1997, com vistas a um aumento substancial da capacidade de C\&T mediante um plano qüinqüenal para o desenvolvimento de C\&T.

O Ministério da Ciência e Tecnologia da Coréia tem a função de atuar como "líder", especializado em áreas em comum, interdisciplinares e estratégicas, e assume responsabilidade pela articulação geral entre todos os demais ministérios e órgãos. A análise das medidas - que tem como meta elevar a Coréia à categoria de economia desenvolvida, apoiada no tripé indústria-educaçãoconhecimento em C\&T - demonstra que foi estruturado naquele país um conjunto de normas e orientações adequadas que estão auxiliando o país a atingir os objetivos políticos propostos.

\section{França}

A política industrial francesa tem concedido fortes estímulos financeiros para viabilizar a montagem de grandes projetos aglutinadores de competências em áreas estratégicas. Essa política está apoiada na utilização de concessão de subsídios e de renúncia fiscal. Os subsídios para financiamento e renúncia fiscal são concedidos para grandes empreendimentos ou para aqueles destinados a áreas estratégicas selecionadas. A agência do governo responsável pela concessão de incentivos financeiros é a DATAR. Por sua vez, as pequenas e médias empresas são contempladas com linhas de crédito subsidiado, como, por exemplo, as dotações concedidas pela Societé Française pour l'Assurance du Capital-Risque. O suporte tecnológico é ofertado às pequenas e microempresas pelo governo francês por meio de programas específicos como ANVAR e ATOUT.

A política industrial da França, nas últimas décadas, tem promovido uma estreita associação de interesses entre o Estado e um núcleo de grandes empresas localizadas em setores dinâmicos da economia, muitas delas com uma significativa participação do capital estatal. As prioridades são orientadas para estimular a criação de capacitação produtiva e tecnológica da indústria, com destaque para os grandes programas públicos nos setores de telecomunicações, aeroespacial e de energia nuclear.

\section{Estados Unidos da América}

O governo dos EUA intervém no mercado tecnológico por meio da concessão de grandes incentivos à acumulação e aplicação de capital privado nessa área. O principal instrumento utilizado pelo governo norte-americano é o uso do poder de compra do Estado em favor de produtores locais (Buy American Act). Além dessa legislação, o governo daquele país utiliza um amplo e generoso programa de financiamento a fundo perdido para o desenvolvimento tecnológico de pequenos e microempresários (Small Business Innovactive Research - SBIR). O volume de subsídios diretos e o uso do poder de compra que foram orientados pelo governo dos EUA às atividades de P\&D, na década de 1990, atingiram cerca de US\$ 100 bilhões ao ano. 


\section{GESTÃO DE INOVAÇÃO: A LEI DE INOVAÇÃO TECNOLÓGICA COMO FERRAMENTA DE APOIO ÀS POLÍTICAS INDUSTRIAL E TECNOLÓGICA DO BRASIL \\ José Matias -Pereira - Isak Kruglianskas}

O grande volume de subsídios concedido pelo governo norte-americano ao setor privado é considerado um instrumento de importância vital para estimular pequenas empresas daquele país a investir em tecnologia. Em relação às grandes empresas industriais, que buscam recursos no mercado de capitais, o apoio do Estado se efetiva por meio de contratações de serviços e compra de produtos fabricados por empresas localizadas no país.

Nos EUA, o apoio governamental de estímulo ao P\&D para facilitar a cooperação entre empresas, universidade e laboratórios federais teve início da década de 1960. Sua expansão, entretanto, ocorreu com a aprovação do Stevenson-Wydler Tecnology Innovation Act, de 1980. A partir dessa lei, o governo norte-americano facilitou o acesso do setor industrial aos laboratórios federais, disponibilizando não apenas infra-estrutura altamente especializada mas também oportunidades de parceria no financiamento e uso por instituições privadas de tecnologias desenvolvidas por instituições públicas de pesquisa. Outra medida institucional importante no campo da pesquisa nos EUA foi a aprovação do Bayh-Dole Act. Essa legislação foi direcionada para a questão de propriedade intelectual uniforme, permitindo às universidades, institutos de pesquisa e pequenas empresas reterem a titularidade de patentes de invenções derivadas de pesquisas financiadas com recursos públicos federais e facultar às instituições beneficiárias desses recursos transferirem tecnologia para terceiros. O BayhDole Act foi responsável pelo aumento significativo do nível de patenteamento nas universidades daquele país.

\section{Japão}

As características e os avanços alcançados pelo Japão no campo da C\&T, nas últimas três décadas, indicam a oportunidade de analisar com especial atenção as políticas industrial e tecnológica daquele país (Freeman, 1987, 1995). Verificourse, ao longo dos anos de 1970, uma significativa mudança qualitativa na estrutura tecnológica do Japão, onde ocorreram profundas mudanças com a reorientação do modelo de desenvolvimento que vinha até então sendo adotado, que era apoiado em indústrias intensivas em energia e outros insumos materiais.

O novo modelo passou a priorizar a capacitação tecnológica e a formação de indústrias intensivas em conhecimento, não-poluidoras e com alto valor agregado. $\mathrm{Na}$ fase inicial, os segmentos eleitos foram a microeletrônica, a aviação, o desenvolvimento de recursos marítimos e energéticos. $\mathrm{Na}$ fase seguinte, foram escolhidos a biotecnologia, os novos materiais e as tecnologias da informação e comunicação. Verifica-se, nesse período, o processo de transição da fase de catching up para a disputa da liderança tecnológica mundial (Albuquerque, 1996).

O Plano Básico para C\&T do Japão, que foi aprovado em 1996, teve como objetivo estabelecer políticas específicas para C\&T em um prazo de cinco anos. No citado Plano Básico se destacam as mudanças institucionais orientadas para a construção de um novo sistema $\mathrm{P} \& \mathrm{D}$, a expansão dos recursos públicos destinados à $\mathrm{P} \& \mathrm{D}$, à criação de novas indústrias com ênfase nas tecnologias de informação e comunicação e à promoção de um consenso nacional acerca da importância de C\&T. Os fundamentos levados em consideração para a sua elaboração foram: a estagnação ocorrida nos últimos anos do montante de recursos globais japoneses destinados a C\&T; os menores recursos aplicados pelo governo japonês neste item comparativamente aos demais países da OCDE; e a necessidade de uma maior flexibilização e competitividade do sistema de P\&D japonês. 


\section{GESTÃO DE INOVAÇÃO: A LEI DE INOVAÇÃO TECNOLÓGICA COMO FERRAMENTA DE APOIO ÀS POLÍTICAS INDUSTRIAL E TECNOLÓGICA DO BRASIL \\ José Matias -Pereira - Isak Kruglianskas}

Foi dada prioridade à pesquisa básica e aplicada em tecnologias da próxima geração, particularmente as tecnologias da informação. Buscava-se, ainda, ampliar os recursos para área de P\&D, enfocando a conservação de energia e ambiente. Destacava-se, entre as demais áreas de interesse, a supercondutividade, os novos materiais, a biotecnologia, a eletrônica, as tecnologias de informação e comunicação, as máquinas, o setor aeroespacial, os recursos naturais, as ciências sociais e médicas. Registre-se aqui que foram desenvolvidos esforços naquele país desde o início da década de 1990 visando avançar o conhecimento em áreas identificadas como importantes fronteiras científicas no próximo milênio, como, por exemplo, o Human Frontier Science Program.

Na década de 1990, por sua vez, a política tecnológica do Japão passa a interagir de maneira mais intensa com a política industrial (Maldonado, 1998). Constata-se, nos princípios gerais das políticas industrial e tecnológica elaborados pelo MITI, para o final da década, a atribuição de três diretrizes básicas: solucionar as questões relativas ao padrão de especialização da indústria japonesa, com forte ênfase em políticas industriais e tecnológicas e, sobretudo, de promoção de clusters regionais; construir uma sociedade e uma economia que levem em conta a questão ambiental e com prioridade no bem-estar social dos cidadãos, cuja tônica é a política energética; e promover a adoção de políticas de investimento e de comércio adequadas a uma economia global baseada em redes, que expressa as prioridades japonesas do ponto de vista internacional (Lastres e Cassiolato, 2000).

A experiência internacional referente às legislações que definem medidas para a promoção da ciência, tecnologia e inovação é reveladora, encontrando apoio nos exemplos aqui assinalados, e serve como ilustração, para comprovar que os países que consideram $C \& T$ como atividade estratégica constroem sistemas legais que estimulam, de forma coordenada, o desenvolvimento científico, tecnológico e a inovação no setor industrial. Sem desconsiderar a dimensão física, a diversidade regional e a complexidade econômica, política, cultural e populacional dos países citados, pode-se argumentar que a consecução das metas na área de ciência e tecnologia passa pela consolidação de um arcabouço legal, cujo conteúdo permita dinamizar a relação entre universidades, institutos de pesquisa e o setor produtivo nacional.

\section{A conexão entre as leis sobre inovação e pesquisa da França e do Brasil}

Abordados os aspectos mais relevantes das políticas industrial e tecnológica dos países mencionados anteriormente (Matias-Pereira, 2005), torna-se possível iniciar a análise da relação e dos aspectos mais relevantes da Lei de Inovação e Pesquisa da França, Lei n. ${ }^{\circ}$ 99-587, e da Lei de Inovação Tecnológica do Brasil, Lei Federal n. ${ }^{\circ}$ 10.973/2004.

A Lei de Inovação e Pesquisa da França, n. ${ }^{\circ}$ 99-587, de 12 de julho de 1999, estabelece os procedimentos legais da relação público-privada, além de criar mecanismos que estimulem a inovação tecnológica no ambiente universitário. Tem como objetivo facilitar a transferência de pesquisa financiada pelo setor público para a indústria e a criação de empresas inovadoras. A experiência mostra que a utilização econômica dos resultados da pesquisa é um fator básico do dinamismo da economia, e o número de empresas criadas a cada ano utilizando os resultados de pesquisa financiada pelo setor público permanece demasiado baixo. São, entretanto, essas empresas que têm o mais forte potencial para crescimento. Observa-se que a citada Lei de Inovação e Pesquisa da França tem como propósito reverter essa tendência e proporcionar um contexto legal que fomente a criação de empresas inovadoras de tecnologia, sobretudo por parte de pessoas jovens, sejam pesquisadores, estudantes ou empregados. 


\section{GESTÃO DE INOVAÇÃO: A LEI DE INOVAÇÃO TECNOLÓGICA COMO FERRAMENTA DE APOIO ÀS POLÍTICAS INDUSTRIAL E TECNOLÓGICA DO BRASIL \\ José Matias -Pereira - Isak Kruglianskas}

Observa-se que a lei francesa está estruturada em quatro seções, que cuidam: da mobilidade dos pesquisadores em direção à indústria e às empresas; da cooperação entre estabelecimento de pesquisa do setor público e empresas; do quadro geral fiscal para empresas inovadoras; e do quadro geral jurídico para empresas inovadoras. A comparação do conteúdo da lei francesa indica que a esta influenciou decisivamente o projeto de Lei de Inovação Tecnológica do Brasil. A similitude entre o teor da Lei de Inovação e Pesquisa da França e o texto do projeto de lei nacional é bastante evidente.

Por sua vez, a Lei de Inovação Tecnológica do Brasil está orientada para: a criação de um ambiente propício a parcerias estratégicas entre universidades, institutos tecnológicos e empresas; o estímulo à participação de instituições de ciência e tecnologia no processo de inovação; e o incentivo à inovação na empresa. Ela também possibilita autorizações para a incubação de empresas no espaço público e a possibilidade de compartilhamento de infra-estrutura, equipamentos e recursos humanos, públicos e privados, para o desenvolvimento tecnológico e a geração de processos e produtos inovadores.

Define, ainda, regras para que o pesquisador público possa desenvolver pesquisas aplicadas e incrementos tecnológicos. Para isso criou mecanismos como: a bolsa de estímulo à inovação e o pagamento ao servidor público de adicional variável não-incorporável à remuneração permanente, ambos com recursos captados pela própria atividade; a participação nas receitas auferidas pela instituição de origem com o uso da propriedade intelectual e a licença não-remunerada para a constituição de empresa de base tecnológica. Autoriza também o aporte de recursos orçamentários diretamente à empresa, no âmbito de um projeto de inovação, sendo obrigatórias a contrapartida e a avaliação dos resultados. São ainda instrumentos desta lei a encomenda tecnológica, a participação estatal em sociedade de propósito específico e os fundos de investimentos. Para o governo federal, a Lei de Inovação Tecnológica, ao estimular a inovação no setor produtivo, irá incentivar a emancipação tecnológica do País e mudar o quadro atual, em que $73 \%$ dos cientistas estão atuando nas instituições públicas e apenas $11 \%$ nas empresas privadas.

\section{As normas definidoras da Lei de Inovação Tecnológica do Brasil}

O Brasil, com a entrada em vigor da Lei de Inovação Tecnológica (LIT), no início de dezembro de 2004, passou a contar com um novo instrumento de fomento à inovação e à pesquisa científica e tecnológica no ambiente produtivo, com vistas à capacitação e ao alcance da autonomia tecnológica e ao desenvolvimento industrial do País. As definições conceituais que levam à compreensão das disposições normativas da LIT estão contidas no Intertítulo I do texto. O Intertítulo II cuida do estímulo à construção de um ambiente de inovação, trazendo os comandos permissivos para a interação profícua entre as entidades de pesquisa e a iniciativa privada. Destaca-se, em especial, a sinergia para viabilização de empresas emergentes, por meio do processo de incubação, e a colaboração com empresas consolidadas. O Intertítulo III está orientado para a geração de estímulos para a participação das entidades públicas de pesquisa no processo de inovação e preocupa-se em definir normas que permitam a transferência e o licenciamento de tecnologia das universidades e institutos de pesquisa públicos do País para o setor produtivo nacional.

A Lei de Inovação Tecnológica busca promover e incentivar o desenvolvimento científico, a pesquisa e a capacitação tecnológicas de forma a viabilizar o desenvolvimento, conforme define os artigos 218 e 219 da Constituição Federal. O estímulo à inovação coloca no mercado produtos e 


\section{GESTÃO DE INOVAÇÃO: A LEI DE INOVAÇÃO TECNOLÓGICA COMO FERRAMENTA DE APOIO ÀS POLÍTICAS INDUSTRIAL E TECNOLÓGICA DO BRASIL \\ José Matias -Pereira - Isak Kruglianskas}

serviços mais competitivos, gera emprego, renda e desenvolvimento. E uma das maneiras de ampliar essa gama de benefícios está nas incubadoras de empresas. Trata-se de um ambiente que proporciona a possibilidade de compartilhamento de infra-estrutura, equipamentos e recursos humanos, públicos e privados, com as empresas nascentes. Nesse aspecto, a nova legislação pretende regularizar a situação das empresas privadas dentro das universidades e criar um sistema de incentivos fiscais para seu desenvolvimento, a começar pela contratação de pesquisadores e empresas sem licitação. Ao colocar a inovação como foco principal, a Lei de Inovação Tecnológica reconhece que não basta para um país fazer tão-só C\&T e P\&D. É preciso transformá-los em novos produtos e processos ou melhorar o que já existe para que os produtos finais sejam desejados pelos mercados nacional e internacional.

Observa-se que a Lei de Inovação Tecnológica está organizada em torno de três eixos: a constituição de ambiente propício a parcerias estratégicas entre as universidades, institutos tecnológicos e empresas; o estímulo à participação de instituições de ciência e tecnologia no processo de inovação; e o incentivo à inovação na empresa. Ela prevê autorizações para a incubação de empresas no espaço público e a possibilidade de compartilhamento de infra-estrutura, equipamentos e recursos humanos, públicos e privados, para o desenvolvimento tecnológico e a geração de processos e produtos inovadores. Também estabelece regras para que o pesquisador público possa desenvolver pesquisas aplicadas e incrementos tecnológicos. Seus principais mecanismos são: bolsa de estímulo à inovação e pagamento ao servidor público de adicional variável não-incorporável à remuneração permanente, ambos com recursos captados pela própria atividade; a participação nas receitas auferidas pela instituição de origem com o uso da propriedade intelectual e a licença não-remunerada para a constituição de empresa de base tecnológica. A Lei de Inovação Tecnológica também autoriza o aporte de recursos orçamentários diretamente à empresa, no âmbito de um projeto de inovação, sendo obrigatórias a contrapartida e a avaliação dos resultados. São ainda instrumentos desta lei a encomenda tecnológica, a participação estatal em sociedade de propósito específico e os fundos de investimentos.

Para potencializar os instrumentos desta lei, o governo federal criou a Agência Brasileira de Desenvolvimento Industrial (ABDI). A Agência, instalada será responsável pela execução e acompanhamento das políticas industrial, tecnológica e de comércio exterior do governo. A ABDI tem como função articular ações e estratégias da política industrial por meio do apoio ao desenvolvimento do processo de inovação e do fomento à competitividade do setor produtivo. É composta por órgãos do Poder Executivo (ministérios do Desenvolvimento, Indústria e Comércio Exterior, da Ciência e Tecnologia e Casa Civil, por exemplo), da sociedade civil (Sebrae, Apex-Brasil e Confederação Nacional da Indústria) e da iniciativa privada. Além disso, o Ministério da Ciência e Tecnologia (MCT) já está trabalhando em um projeto de lei criando regime fiscal favorável à inovação.

\section{RESULTADOS DA PESQUISA}

Diante da amplitude e complexidade do tema inovação tecnológica tornou-se necessária a realização de entrevistas qualitativas para elevar o nível de consistência do estudo. Isso ficou mais evidente com a divulgação do estudo realizado pela Associação Nacional de Pesquisa, Desenvolvimento e Engenharia das Empresas Inovadoras (Anpei, julho de 2004), que mostra que, das 72 mil empresas pesquisadas, 
apenas 22,6 mil (31,5\% do total) realizaram algum tipo de inovação de produto ou processo produtivo entre 1998 e 2000. Do total de empresas que criaram algo novo, apenas $4 \%$ lançaram produtos que não existiam no mercado. É preocupante, na análise da pesquisa, além do número baixo de empresas inovadoras, a constatação de que $67 \%$ delas declararam que as novas tecnologias e produtos são pouco importantes para sua estratégia. $\mathrm{O}$ estudo sinaliza que entre os entraves que impedem o financiamento à Pesquisa e Desenvolvimento (P\&D) estão as altas taxas de juros, a correção monetária, a lentidão no processo de aprovação de projetos, a burocracia, a confiabilidade no recebimento dos recursos e as exigências excessivas. A captação de recursos é dificultada, também, pela exigência da apresentação de um Plano de Desenvolvimento Industrial (PDI), no qual as empresas devem detalhar sua estratégia de inovação de longo prazo. Isso explicaria, em parte, porque, no período de 2001-2003, apenas quatro PDIs foram apresentados ao governo. Veja a seguir os resultados das pesquisas qualitativas no Quadro 1 .

\title{
Quadro 1. Pesquisa Qualitativa: Características e Fragilidades da Lei de Inovação Tecnológica
}

\begin{abstract}
Tendo como objetivo identificar as principais características e fragilidades da Lei de Inovação Tecnológica do Brasil, realizamos um total de 13 entrevistas abertas, no período de junho de 2004 a abril de 2005, com atores dos principais segmentos envolvidos no debate da construção da Lei de Inovação Tecnológica: representantes do setor privado (3), do parlamento (1), do governo (1), juristas (2) e pesquisadores das universidades e centros de pesquisas (6). Dessas entrevistas podemos destacar o seguinte:
\end{abstract}

a) A criação de mecanismos jurídicos e financeiros para as empresas, universidades e cientistas interagirem, na procura por soluções inovadoras, foi aceita pela maioria dos entrevistados como uma medida necessária, visto que a parceria até então existente ocorria de forma precária e com um nível baixo de transparência. Espera-se, a partir da Lei de Inovação Tecnológica e de sua regulamentação, que se abram novas possibilidades para que as partes constituam fundos, criem sociedades anônimas, tomem empréstimos, recebam os incentivos e dividam as patentes;

b) Para uma parcela significativa dos cientistas entrevistados a lei é positiva, conceitualmente falando, por reconhecer a empresa como o local da inovação. Para esse segmento existe uma sinalização clara de que o governo federal está orientando medidas para a geração de estímulos à inovação, flexibilizando atividades e relações das instituições científicas e tecnológicas. Para eles, a lei busca enfrentar o desafio de criar no Brasil as condições necessárias para que o País possa dar um salto consistente no campo tecnológico, em particular quando reconhece que entre as soluções apontadas para corrigir rumos está incrementar a interação entre instituições científicas e tecnológicas - incluindo os Centros de Educação Tecnológica - e o parque produtivo;

c) Entre as medidas necessárias para o desenvolvimento das inovações no País, em particular as medidas defendidas pelos empresários, destacam se as que sustentam que as despesas de P\&D sejam deduzidas no lucro tributável; desoneração dos investimentos de $\mathrm{P} \& \mathrm{D}$; definição de incentivos diretos para a formação dos empresários em know-how empresarial, estratégias de marketing, diferenciação competitiva e princípios de P\&D; oferta de incentivos diretos para a formação da infra-estrutura de $\mathrm{P} \& \mathrm{D}$; financiamentos privilegiados de pesquisa para projetos envolvendo universidade-indústria; apoio financeiro e técnico-jurídico para patenteamento de novas descobertas realizadas no Brasil e no exterior; 
d) Todos os juristas entrevistados sustentam que existem imperfeições e carências no teor da Lei de Inovação Tecnológica, como, por exemplo, sua amplitude e excesso de detalhes, a falta de definições claras para a geração de estímulos e apoio a micro e pequenas empresas do País. Destacam, também, as falhas na forma de definição das normas que tratam da interação entre os três atores principais para o sucesso da Lei de Inovação Tecnológica, ou seja, o inventor, a universidade e os institutos de pesquisa, e o capital de risco. Para eles, a LIT não definiu, também, as regras dessa relação em contrato, que ainda permanecem obscuras. Essas constatações reforçam a argumentação dos entrevistados de que a implementação das medidas definidas na Lei de Inovação Tecnológica irá exigir o envolvimento de toda a sociedade organizada na sua regulamentação, para que possa sanar esses defeitos e vir a cumprir os seus objetivos, em particular na geração dos estímulos adequados à inovação, flexibilizando atividades e as relações das instituições científicas e tecnológicas;

e) A argumentação utilizada pelo governo federal - tendo como base a legislação existente nos países mais avançados - para permitir o afastamento de pesquisadores empreendedores, a fim de que possam desenvolver atividade empresarial relativa à produção de bens diretamente decorrentes de criação de sua autoria, que irá permitir transformar o conhecimento em bens tangíveis para a sociedade, é aceita pela maioria dos entrevistados. Eles ressaltam - professores-pesquisadores de universidades públicas e centros de pesquisa - a necessidade de analisar com maior profundidade os riscos de um esvaziamento das universidades públicas, considerando que no texto da proposta não se prevêem mecanismos que permitam às universidades controlar adequadamente o trabalho dos pesquisadores que se afastarem para desenvolver projetos de pesquisa no setor privado. Nesse sentido, defendem que a regulamentação da Lei de Inovação Tecnológica deve preocupar-se principalmente com a transparência na relação entre os professores das universidades e empresas;

f) No que tange à gestão da inovação, existe uma percepção por parte de uma parcela dos professorespesquisadores de que a lei é carente de normas definidoras que permitam às universidades controlar melhor o trabalho dos pesquisadores que venha m a se afastar do ambiente acadêmico para desenvolver projetos no setor privado. Na opinião dos entrevistados, é indesejável para a sociedade que o interesse do pesquisador prevaleça em relação ao da instituição a que ele está ligado. Nesse sentido, argume ntam que é preciso preservar os interesses das instituições de pesquisa para impor limites à iniciativa privada. Observa-se que uma parcela dos professores que atuam como consultores ou que executam projetos para o setor privado usa as fundações de apoio das universidades, que firmam contratos e movimentam recursos praticamente sem prestar contas às universidades. Caso isso não seja corrigido na regulamentação da Lei de Inovação Tecnológica, corre-se o risco de o interesse do pesquisador acabar prevalecendo em relação ao da instituição a que ele está ligado. Sob essa óptica, a lei não está sendo aceita pacificamente por uma parcela de professores, pesquisadores e dirigentes de associações de docentes como uma solução para os problemas de desenvolvimento tecmológico brasileiro. Para esse segmento, a lei representa mais um estágio no processo de aprofundamento da privatização do setor público. Argumentam que o papel das universidades públicas não é o de fornecer mão-de-obra e capacidade instalada a custo zero para o setor privado nem pagar a conta da falta de investimento estratégico em tecnologia. Seu papel é estabelecer um ambiente em que a pesquisa - e não a adaptação tecnológica - e o ensino crítico e de qualidade, bem como a extensão, são exercidos de modo indissociável, propiciando bases sólidas para o desenvolvimento social, cultural e tecnológico do País;

g) A maioria dos entrevistados - em particular os empresários e os pesquisadores - entende que o processo de estruturação de competências tecnológicas e organizacionais no interior das firmas requer um amplo e constante acesso às fontes de informação básica, visando transformar informações em 


\section{GESTÃO DE INOVAÇÃO: A LEI DE INOVAÇÃO TECNOLÓGICA COMO FERRAMENTA DE APOIO ÀS POLÍTICAS INDUSTRIAL E TECNOLÓGICA DO BRASIL José Matias -Pereira - Isak Kruglianskas}

conhecimento. Para que isso ocorra, as empresas - cujo propósito é desenvolver seus próprios sistemas de aprendizado tecnológico e organizacional - precisam criar departamentos específicos de P\&D (Roussel, Saad e Bohlin, 1992). Assim, argumentam que a Lei de Inovação Tecnológica não levou em consideração a essencialidade dessas questões, visto que sem tecnologia as possibilidades de competir nos mercados mundiais ficam comprometidas. Nesse sentido, sustentam que a criação e a manutenção dos centros de $\mathrm{P} \& \mathrm{D}$ e a conseqüente valorização dos recursos humanos altamente qualificados que atuam nesses centros devem ser uma medida prioritária para o País. Esse esforço irá contribuir para reduzir o papel das empresas multinacionais como principais produtoras e detentoras de tecnologia de ponta. A geração de estímulos para elevação na prioridade dada pelas empresas para a área de ciência e tecnologia tem como propósito evitar que continue ocorrendo o processo de desmantelamento de centros de $\mathrm{P} \& \mathrm{D}$ e a conseqüente dispensa de recursos humanos de alto nível;

h) A Lei de Inovação Tecnológica, para uma parcela dos entrevistados, irá contribuir para consolidar a relação entre produção, pesquisa e União, visto que busca desenvolver esforços de diversos ministérios e da sociedade. Entendemos que a relação com o setor privado não deve enfraquecer as universidades, porque sem elas não haverá bens de conhecimento e, sem bens de conhecimento, não há transferência, inovação ou produção. Por sua vez, diversos aspectos e desafios precisam ser vencidos como a integração da Lei de Inovação Tecnológica à nova política industrial e sua ação coordenada às políticas estaduais e municipais;

i) Todos os entrevistados concordaram que a LIT somente produzirá resultados concretos se as indústrias necessitarem inovar. Lembram, entretanto, que o processo de inovação não ocorre pela oferta de mecanismos, mas quando é gerada a necessidade de inovar. A demanda P\&D por parte da empresa decorre da sua necessidade de competir em novos mercados, com níveis de exigências mais sofisticados, visto que suas vendas não estarão ocorrendo em função do preço, mas pela qualidade do produto e do segmento do mercado. Dessa forma, a LIT apenas abre possibilidades, mas não garante que as agências de governo incentivem adequadamente o uso dos instrumentos disponíveis;

j) Os representantes do setor privado entendem que a decisão das empresas transnacionais ou globais de implantar novos centros de tecnologia, ou seja, liderar o País, com pesquisa nacional, o desenvolvimento de novos produtos depende de diversos fatores. Na maioria dessas empresas não existe, necessariamente, uma matriz concentrando todas as relações de P\&D. Assim, para cada segmento de negócios pode-se ter várias competências em países diferentes. Dessa forma, argumentam que a cooperação entre empresa e academia não basta. É necessário existir um arcabouço institucional consistente, a partir de uma política industrial e tecnológica coerente, que permita que os dirigentes dessas empresas globais possam confiar a brasileiros a gestão de um centro de tecnologia. No Brasil isso já vem ocorrendo com a política de fomento na área de informática, por meio da Lei de Informática, que viabilizou a produção local, exigindo uma contrapartida de investimento das empresas em P\&D. Diversas empresas, como a Motorola, a HP e a Siemens, se beneficiaram dessa política e criando assim mais emp regos e firmando parcerias com universidades.

\section{CONSIDERAÇÕES FINAIS}


As análises e os argumentos utilizados neste artigo permitiram responder, mesmo que parcialmente, a pergunta formulada no início deste artigo. Nela questionamos se "a Lei de Inovação Tecnológica aceita como parte essencial do arcabouço institucional para fortalecer as áreas de pesquisa e da produção de conhecimento no Brasil - poderá fomentar adequadamente a criação de novos ambientes, propícios à geração e absorção de inovações, atuando como ferramenta de apoio às políticas industrial e tecnológica do Brasil". Verifica-se que, nessa análise, ficaram algumas dúvidas relevantes sobre a consistência da Lei de Inovação Tecnológica, que, entre outros aspectos, deve funcionar como instrumento de suporte para romper o ciclo vicioso da dependência tecnológica do País. Nesse sentido, destacamos os pontos a seguir.

Em primeiro lugar, a Lei de Inovação Tecnológica, ao buscar estabelecer um diálogo cada vez mais intenso entre as instituições produtoras de bens de conhecimento e as produtoras de bens e serviços, surge como mais um instrumento para facilitar a criação de uma cultura de inovação no País. Sua aprovação, entretanto, não é suficiente para mudar a realidade atual existente nesse campo. Observa-se que os instrumentos estão sendo disponibilizados, mas é preciso um maior envolvimento e compromisso por parte dos atores envolvidos no assunto. Inúmeras questões complexas não foram tratadas nesta lei, como a criação de mecanismos que permitam sua efetiva conexão com as políticas industrial e tecnológica, bem como a falta de flexibilidade de gestão das instituições de pesquisa, ou seja, a excessiva rigidez que prevalece na gestão de recursos humanos, financeiros e materiais.

Em segundo, a inovação tecnológica, submetida a uma concepção de desenvolvimento, deve resultar da interação entre pesquisadores, agentes econômicos, grupos sociais, indivíduos e órgãos estatais, configurando um ponto de convergência entre as potencialidades científicas e as necessidades econômicas e sociais. Na área de gestão da inovação, a lei se restringe ao estabelecimento de regimes de comercialização das inovações geradas nas instituições científicas e tecnológicas. Por sua vez, o processo de construção de competências tecnológicas e organizacionais,no interior das firmas exige, entretanto, que se viabilize um amplo e constante acesso às fontes de informação básica, visando transformar informações em conhecimento. Para que isso ocorra, é preciso que sejam gerados estímulos para as empresas criarem departamentos específicos de P\&D.

Em terceiro lugar, a Lei de Inovação Tecnológica faz parte de um ciclo que partiu da discussão focada nos recursos e atingiu os aspectos institucionais que agora precisam ser implementados. Trata-se de uma lei muito incipiente, e sua regulamentação vai requerer um diploma legal significativamente extenso. Na regulamentação da lei existem aspectos que necessitam de um maior detalhamento, de forma a preservar a identidade tanto das universidades quanto das indústrias e empresas, para que, de fato, ela possa tornar-se um instrumento relevante de fomento às políticas industrial e tecnológica do País. Dessa forma, evidencia-se que é necessário ir mais além da aprovação e regulamentação da Lei de Inovação Tecnológica, visto que ela não se esgota em si mesma. Para superar essas dificuldades e atingir seus propósitos, a implementação da Lei de Inovação Tecnológica vai exigir que ocorra uma efetiva interação das ações governamentais com o segmento privado, a comunidade científica e tecnológica e os trabalhadores.

Concluímos, assim, que cabe ao Estado orientar, apoiar e estimular o processo de inovação tecnológica no País, sem desconsiderar que a transformação da indústria é responsabilidade dela própria. Nesse contexto, a Lei de Inovação Tecnológica surge como um instrumento institucional relevante para apoiar as políticas industrial e tecnológica no Brasil. 
NOTA

Este artigo é parte dos resultados da pesquisa "Gestão de Políticas de Proteção à Propriedade Intelectual no Brasil", elaborada por um dos autores no âmbito do Programa de Pós-Doutorado em Administração da Universidade de São Paulo (FEA/USP), sob a supervisão do Prof. Dr. Isak Kruglianskas, Coordenador de Pós-Graduação em Administração da FEA/USP. A referida pesquisa, iniciada em junho de 2004 e concluída em 31 de maio de 2005, foi apoiada pelo Programa de PósGraduação em Administração da Universidade de Brasília (PPGA/UnB).

\section{REFERÊNCIAS BIBLIOGRÁFICAS}

AGUIAR, A. C. Coordenação de uma rede nacio nal de informação em Ciência e Tecnologia: um plano prioritário do IBICT. Ciência da Informação, v. 9, n.1/2, p. 83-8, 1981.

AGUIAR, A. C. Informação e atividades de desenvolvimento científico, tecnológico e industrial. Ciência da Informação, v. 20, n. 1, p. 7-15, 1991.

ALBUQUERQUE, E. M. Do catching up à fronteira tecnológica: notas sobre políticas industriais e a construção do sistema nacional de inovação no Japão. In: CASSIOLATO, J. E. (coord.). Projeto de Pesquisa: Novas Políticas Industriais e Tecnológicas. Rio de Janeiro: Instituto de Economia da UFRJ, 1996.

AZEVEDO, F. (org.). As ciências no Brasil. Rio de Janeiro, RJ: Editora UFRJ, 1994. 2 v.

BRASIL. Projetos de Leis n. ${ }^{\circ}$ 7.282/2002 e 3.476/2004, do Poder Executivo, Brasília, DF: Congresso Nacional, CD, 2004.

BRASIL. Lei de Inovação Tecnológica (Lei n. ${ }^{\circ}$ 10.973/2004). Brasília, DF: Congresso Nacional. Atos do Poder Legislativo, DOU, n. ${ }^{\circ} 232$ de 03.12.2004.

BRASIL. Constituição da República Federativa do Brasil de 1988, Brasília, DF: Senado Federal, 2005.

BRASIL. Presidência da República. "Orientação Estratégica de Governo: Crescimento Sustentável, Emprego e Inclusão Social”, Brasília, DF: PR, 2003. Disponível em: <http://www.presidencia.gov.br>. Acesso em: 11 maio 2005. 


\section{GESTÃO DE INOVAÇÃO: A LEI DE INOVAÇÃO TECNOLÓGICA COMO FERRAMENTA DE APOIO ÀS POLÍTICAS INDUSTRIAL E TECNOLÓGICA DO BRASIL \\ José Matias -Pereira - Isak Kruglianskas}

BRASIL. Ministério do Desenvolvimento, Indústria e Comércio Exterior. Diretrizes de Política Industrial, Tecnológica e Comércio Exterior, Brasília, DF: MDICE, 2004. Disponível em: <http://www.mdice.gov.br>. Acesso em: 25 maio 2005.

BRASIL. Ministério do Planejamento, Orçamento e Gestão. Plano Plurianual - Avança Brasil 2000/2003, Brasília, DF: PR/MPOG, 2000.

BRASIL. Ministério do Planejamento, Orçamento e Gestão. Plano Plurianual - 2004/2007, Brasília, DF: PR/MPOG, 2004. Disponível em: <http://www.planejamento.gov.br>. Acesso em: 13 jun. 2005.

BRASIL. Ministério da Ciência e Tecnologia - MCT. Projeto de Diretrizes Estratégicas para a Ciência, Tecnologia e Inovação em um Horizonte de 10 Anos. Brasília, DF: DECTI/MCT, 2000.

BRASIL. Ministério da Ciência e Tecnologia - MCT. Conferência Nacional de Ciência, Tecnologia e Inovação. Anais. Brasília, DF: CNPq/MCT, 2001a.

BRASIL. Ministério da Ciência e Tecnologia - MCT. Livro Verde da Ciência, Tecnologia e Inovação, Brasília, DF: CNPq/MCT, 2001b.

BRASIL. Ministério da Ciência e Tecnologia - MCT. Livro Branco da Ciência, Tecnologia e Inovação, Brasília, DF: CNPq/MCT, 2002.

BRISOLLA, S. Indicadores quantitativos de ciência e tecnologia no Brasil, Campinas, SP: Núcleo de Política Científica e Tecnológica da Universidade de Campinas, 1993.

BURRELL, G.; MORGAN, G. Sociological paradigms and organizational analysis. London: Heinemann, 1979.

CALDAS, R. C. A construção de um modelo de arcabouço legal para a Ciência, Tecnologia e Inovação. Parcerias Estratégicas, v. 11, p. 5-27, 2001.

COUTINHO, L. G. Superação da fragilidade tecnológica e a ausência de cooperação. In: VOGT, C.; STAL, E. (orgs.). Ciência e tecnologia: Alicerces do desenvolvimento, Brasília, DF: CNPq, 1999. p. 107-24.

COUTINHO, L. G.; FERRAZ, C. (orgs.). Estudo da competitividade da indústria brasileira, Campinas, São Paulo: Editora Unicamp/Papirus/MCT, 1994.

CASSIOLATO, J. E. As novas políticas de competitividade: a experiência dos principais países da OCDE, T.D. 367, Rio de Janeiro: IE/IFRJ, julho, 1996.

CIRILLO, W. Caminhos para a inovação, Revista Uniemp, n. 30, p. 18-20, 2004. Disponível em: <http://home.uniemp.org.br/revista/uniemp_informativo30_nov04_pg04a06.pdf>. Acesso em: 12 maio 2005 .

CRUZ, C. H. B. A universidade a empresa e a pesquisa que o país precisa. Revista Humanidades, v. 45, Editora Universidade de Brasília, 1999. 


\section{GESTÃO DE INOVAÇÃO: A LEI DE INOVAÇÃO TECNOLÓGICA COMO FERRAMENTA DE APOIO ÀS POLÍTICAS INDUSTRIAL E TECNOLÓGICA DO BRASIL \\ José Matias -Pereira - Isak Kruglianskas}

CRUZ, C. H. B. Avaliação do projeto da lei de inovação: o lugar da inovação. Fórum da Lei de Inovação, Centro Minerva de Empreendedorismo, Escola Politécnica da Universidade de São Paulo. Boletim Inovação Unicamp, 20.05.2004.

DAHLMAN, C.; FRISCHTAK, C. National systems supporting technical advance in industry. Industry Series Paper, n 1, p. 32-44, 1990.

DAHRENDORF, R. Class and class conflict in industrial society. Stanford, CA: Stanford University Press, 1959.

ERBER, F. O padrão de desenvolvimento industrial e tecnológico e o futuro da indústria brasileira. Revista de Economia Contemporânea, v. 4, número especial, 2000.

FRANÇA. Lei sobre Inovação e Pesquisa Francesa, 1999. Disponível em

<http://www.education.gouv.fr/technologie>. Acesso em: 25 abr. 2005.

FREEMAN, C. The economics of technical change: critical survey. Cambridge Journal of Economics, v. 18 , p. 463-514, 1984.

FREEMAN, C. Technology Policy and Economic Performance: Lessons from Japan Pinter, 1987.

FREEMAN, C. The National System of Innovation in historical perspective. Cambridge Journal of Economics, v. 19, n.1, 1995.

FREEMAN, C.; SOETE, L. The economics of industrial innovation. London: Pinter, 1994.

IBGE. Censo 2000, Rio de Janeiro, RJ: IBGE. 194 p., 2002.

IBGE. Indicadores econômicos, Rio de Janeiro, RJ: IBGE, 2003. Disponível em $<$ http://www.ibge.gov.br>.

IBGE. Indicadores econômicos. Rio de Janeiro, RJ: IBGE, 2004.

IEDI. Políticas industriais em países selecionados. São Paulo: IEDI, 1998.

INPI. Lei da Propriedade Industrial (Lei n. ${ }^{\circ}$ 9.279/96), Rio de Janeiro: INPI, 1996.

JAPAN, Cabinet Decision, Science and Technology Basic Plan. Disponível em <http://www.cabinet.gov.jp>. Acesso em: 12 jun. 2005.

LASTRES, H. M. M. Dilemas da política científica e tecnológica. Ciência da Informação, v. 24, n. 2, p. 1-8, 1995.

LASTRES, H. M. M.; ALBAGLI, S. (eds.). Informação e globalização na era do conhecimento. Rio de Janeiro: Campus, 1999.

LASTRES, H. M. M.; CASSIOLATO, J. E. A Política Tecnológica Japonesa. SEMINÁRIO SOBRE O JAPÃO, 2000, Rio de Janeiro. Anais. Rio de Janeiro, 2000. 


\section{GESTÃO DE INOVAÇÃO: A LEI DE INOVAÇÃO TECNOLÓGICA COMO FERRAMENTA DE APOIO ÀS POLÍTICAS INDUSTRIAL E TECNOLÓGICA DO BRASIL \\ José Matias -Pereira - Isak Kruglianskas}

LORA, E. Competitividade: O motor do crescimento, Washington, DC: BID, 2001.

MALDONADO, J. Política Industrial no Japão. Relatório NPI 06.1/98, Projeto de Pesquisa Apoiado pelo Instituto de Estudos para o Desenvolvimento Industrial - IEDI, Rio de Janeiro, RJ: IE/UFRJ, 1998.

MATESCO, V. (coord.). O atraso brasileiro na inovação tecnológica. Rio de Janeiro, RJ: IBRE/FGV, 2001.

MATIAS-PEREIRA, J. Ciência e tecnologia e desenvolvimento no Brasil. Brasília, DF: PPGA-UnB. Pesquisa Apoiada pelo Fundo de Pesquisa da Universidade de Brasília - DPP/UNB. 154 p., 2002a.

MATIAS-PEREIRA, J. Science, Technology and Development in Brazil: The importance of creating a research culture in business and an entrepreneurial culture in the universities. In: BALAS 2002 ANNUAL CONFERENCE. Tampa. Anais. The University of Tampa Press: BALAS, 2002b.

MATIAS-PEREIRA, J. A Lei de Inovação Tecnológica como instrumento de apoio à construção de um modelo tecnológico autônomo no Brasil. In: ALTEC CONFERENCE 2003, México. Anais. México: ALTEC, 2003.

MATIAS-PEREIRA, J. The Importance of the Construction of Law of Brazilian Technological Innovation”. In: IBEROAMERICAN CONFERENCE, 2003, São Paulo . Anais. São Paulo, 2003b.

MATIAS-PEREIRA, J. Avaliação do projeto da lei de inovação. Debatedor. In: FÓRUM DE LEI DE INOVAÇÃO, São Paulo. Anais. São Paulo:POLI-USP, 2004.

MATIAS-PEREIRA, J. A Lei de Inovação como Instrumento de Suporte à Política Industrial e Tecnológica do Brasil. Revista do Centro de Ciências Administrativas, v. 9, n. 1, p. 18-33, 2005.

MATIAS-PEREIRA, J.; KUGLIANSKAS, I. Gestão de Políticas de Proteção à Propriedade Intelectual no Brasil. In: SIMPÓSIO DE GESTÃO DE INOVAÇÃO TECNOLÓGICA, 23., 2004, Curitiba. Anais. Curitiba: NPTG-USP/ANPAD, 2004.

MATIAS-PEREIRA, J.; KUGLIANSKAS, I.; MARCELINO, G. Industrial and technological policies as inductive development. In: THE $5^{\text {th }}$ TRIPLE HELIX CONFERENCE, 2005, Turin. Anais. Turin: TRIPLE HELIX, May 2005.

MORGAN, G. Paradigms, Metaphors, and Puzzle Solving in Organization Theory. Administrative Science Quartely, v. 25, p. 605-22, 1980.

OCDE. Main Science and Technology Indicators, 2, Paris: OCDE, 1997a.

OCDE. Diffusing technology to industry: government policies and programmes, Working Paper, vol. V, 33., Paris: OCDE, 1997b.

OCDE. Industrial competitiveness, Paris: OCDE, 1996.

OCDE. Managing national innovation systems, Paris: OCDE, 1999. 


\section{GESTÃO DE INOVAÇÃO: A LEI DE INOVAÇÃO TECNOLÓGICA COMO FERRAMENTA DE APOIO ÀS POLÍTICAS INDUSTRIAL E TECNOLÓGICA DO BRASIL \\ José Matias -Pereira - Isak Kruglianskas}

OCDE. Brazil - Economic survey, Paris: OCDE, 2001.

OCDE. Medição de atividades científicas e tecnológicas. Manual Frascati. Brasília: CNPq, 1979.

PAVITT, K. The social shape of the national science base. Research Policy, v. 27, n. 8, p. 793-805, 1998.

PAVITT, K. What makes basic research economically useful? Research Policy, v. 20, n. 2, p. 109-19, 1991.

PNUD. Human Development Report 2003: Millennium Development Goals: A compact among nations to end human poverty. New York: Oxford University Press for the UNDP, 2003.

PNUD. Informes sobre el desarrollo humano, Brasília, DF: PNUD-IPEA, 2002.

ROUSSEL, P. A; SAAD, K. N.; BOHLIN, N. Pesquisa \& Desenvolvimento. São Paulo, SP: Makron Books, 1992.

SCHWARTZMAN, S. Um espaço para a ciência: A formação da comunidade cientifica no Brasil. Brasília, DF: CNPq/MCT, 2001.

SCHWARTZMAN, S. (coord.). Ciência e tecnologia no Brasil: uma nova política para um mundo global. Rio de Janeiro: Editora da Fundação Getulio Vargas, 1995. 3 v.

SCHWARTZMAN, S. et al. Ciência e tecnologia no Brasil: Uma nova política para um mundo global. In: SCHWARTZMAN, S. (coord.), Ciência e tecnologia no Brasil: política industrial, mercado de trabalho e instituições de apoio. Rio de Janeiro: Editora da Fundação Getulio Vargas, 1995. p. 1-59.

SIMON, H. A. Theories of decision-making in economics and behavioral science. The American Economic Review, v. 49, n. 3, p. 253-83, jun., 1959.

SIMON, H. Comportamento administrativo. Rio de Janeiro: Editora da Fundação Getulio Vargas, 1965.

SIMON, H. A. Rationality as process and as product of thought. American Economic Review, v. 68, $\mathrm{n}$. 2, p. 1-16, 1978.

SHIN, T. et al. The first survey for Science and Technology Forecasting; Korea's Future Technology. Seoul: Science and Technology Policy Institute (STEPI), 1994.

STEPI (Science and Technology Policy Institute). A Long-range Plan for Science and Technology toward the Year 2010. Seoul: Science and Technology Policy Institute (STEPI), 1995. 


\title{
GESTÃO DE INOVAÇÃO: A LEI DE INOVAÇÃO TECNOLÓGICA COMO FERRAMENTA DE APOIO ÀS \\ POLÍTICAS INDUSTRIAL E TECNOLÓGICA DO BRASIL \\ José Matias -Pereira - Isak Kruglianskas
}

\section{Artigo recebido em 08.04.2003. Aprovado em 08.12.2004.}

\author{
José Matias-Pereira \\ Professor e pesquisador do Programa de Pós-Graduação em Administração da Universidade de \\ Brasília. Doutor em Ciência Política pela Universidade Complutense de Madrid - Espanha. Pós-Doutor \\ pelo Programa de Pós-Doutorado em Administração da Universidade de São Paulo (FEA/USP). \\ Interesses de pesquisa nas áreas de gestão da inovação tecnológica, finanças públicas e administração \\ pública. \\ E-mail: matias@unb.br; matias.pereira@brturbo.com.br \\ Endereço: SHIS QI 26 Conj. 5, casa 22, Lago Sul, Brasília - DF, 71670-050.
}

\section{Isak Kruglianskas}

Professor do Departamento de Administração da FEA/USP. Coordenador do Programa de PósGraduação em Administração da Universidade de São Paulo. Doutor em Administração pela FEA/USP. Interesses de pesquisa nas áreas de gestão da inovação tecnológica e gestão ambiental na empresa.

E-mail: ikruglia@usp.br

Endereço: Av. Professor Luciano Gualberto, 908, sah E117, Cidade Universitária, São Paulo - SP, 05508-900. 